\title{
LA INCONSTITUCIONALIDAD DE LOS PARTIDOS. A PROPÓSITO DE LA LEY 6/2002 DE PARTIDOS POLÍTICOS
}

ANTONIOTORRES DEL MORAL

Catedrático de Derecho Constitucional UNED 


\section{SUMARIO}

1. INTRODUCCIÓN. 2. ETA Y SU ENTORNO. 3. LA MUY DEFICIENTE LEGISLACIÓN SOBRE PARTIDOS DE 1978. 4. NECESIDAD DE MODERNIZAR DICHA LEGISLACIÓN. CONVERGENCIA DE LAS ACCIONES LEGISLATIVAY JURISDICCIONAL ENTORNO A LA SUSPENSIÓN, DISOLUCIÓN E ILEGALIZACIÓN DE LOS PARTIDOS POLITICOS. 5. DIVISIÓN DE LA DOCTRINA ACERCA DE LA CONSTITUCIONALIDAd DE LA LEY ORgánICA 6/2002, DE 27 DE JUNIO, Sobre Partidos Políticos. 6. AnÁlisis de La Ley. Sentencias del. Tribunal Constitucional 48/2003, DE 12 DE MARZO. 6.1. Fuera complejos. 6.2. El ambiente internacional antiterrorista después de la destrucción de las Torres Gemelas de Nueva York y el casi simultáneo ataque al Pentágono. 6.3. Aspectos criticables u opinables de la Ley. 6.4. La actividad de los partidos y su posible ilegalización. 6.5. No se trata de un juicio penal. 6.6. Apoyo tácito al terrorismo. 6.7. Competencia juzgadora. 6.8. Democracia militante. 6.9. Las candidaturas de las agrupaciones de electores. 7. OTROS ASPECTOS DE LA LEY Y DE LAS SENTENCIAS 48/2003 Y 5/2004. 8. CONCLUSIÓN. 9. EPilogo: ACTIVIDAD DE LOS TRIBUnales Supremo y Constitucional españoles, del Parlamento Europeo Y del Tribunal Europeo de Derechos humanos. 


\title{
LA INCOSTITUCIONALIDAD DE LOS PARTIDOS POLÍTICOS. A PROPÓSITO DE LA LEY ORGÁNICA 6/2002 DE PARTIDOS POLÍTICOS
}

POR

\author{
ANTONIOTORRES DEL MORAL \\ Catedrático de Derecho Constitucional \\ UNED
}

\section{INTRODUCCIÓN}

La Constitución española dedica varios artículos al fenómeno asociativo y al corporativo (asociaciones, partidos políticos, colegios profesionales, asociaciones de usuarios y consumidores). De todos esos pasajes, nos vamos a fijar en dos solamente, por ser los pertinentes a este trabajo: el artículo 22, que regula el derecho de asociación, y el $6^{\circ}$, que constitucionaliza por primera vez en España a los partidos políticos. Dice el primero de ellos:

"Artículo 22.- 1. Se reconoce el derecho de asociación. 2. Loas asociaciones que persigan fines o utilicen medios tipificados como delitos son ilegales. 3. Las asociaciones constituidas al amparo de este artículo deberán inscribirse en un registro a los solos efectos de publicidad. 4. Las asociaciones sólo podrán ser disueltas o suspendidas en sus actividades en virtud de resolución judicial motivada. 5 . Se prohíben las asociaciones secretas y las de carácter paramilitar». 
Por su parte, los partidos políticos son regulados del siguiente tenor:

"Artículo $6^{\circ}$.- Los partidos políticos expresan el pluralismo político, concurren a la manifestación y formación de la voluntad popular $y$ son instrumento fundamental para la participación política. Su creación y el ejercicio de su actividad son libres dentro del respeto a las Constitución y a la ley. Su estructura interna y su funcionamiento deberán ser democráticos".

Reparemos en que únicamente se habla de fines al tratar del derecho de asociación, especificando que dichos fines deben ser tipificados como delito para considerar ilegales las asociaciones, ilegalidad que obviamente requerirá un juicio penal, pues que de delitos se trata. Cuando la Constitución aborda los partidos políticos no habla en estos términos, sino en otros que los configuran como asociaciones especiales (de otro modo no se explica su regulación separada). Que les alcancen las garantías del derecho de asociación no empece a lo anteriormente dicho. Dicha especialidad les viene conferida por las funciones que se les reconocen y por las condiciones que se prescriben para su creación, su estructura interna y su funcionamiento. Sobre estos extremos tendremos oportunidad de volver más adelante.

Hace ya no tan pocos años J. J. Solozábal habló de la refractariedad de los partidos a su tratamiento jurídico, a pesar de la importancia que tienen $^{1} ; y$, en igual sentido, C. Fernández-Miranda insistió en la dificultad de una regulación coherente y eficaz de los mismos ${ }^{2}$ habida cuenta de los muy diversos y aun encontrados (al menos aparentemente) ingredientes que hay que cohonestar entre sí. Ingredientes que pueden ser resumidos, como hace A. Rodríguez Díaz, en dos principios: el de constitucionalización y el de constitucionalidad de tales partidos ${ }^{3}$.

Por mi parte, no es la primera vez que me he referido a los problemas de la disciplina juridica de los partidos, de diversas facetas de la democracia y de la reforma constitucional. No he acertado, sin embargo, a conectar los tres asuntos en una visión globalizadora que vertebrara tan

1 SOLOZÁBAL, J. J.: “Sobre la constitucionalización de los partidos politicos en el Derecho constitucional y en el ordenamiento español", en Revista de Estudios Políticos, $\mathrm{n}^{\circ} 45$ (NE), Madrid, 1985, pág. 155.

2 FERNÁNDEZ -MIRANDA CAMPOAMOR, C.: "La pretensión estatal de someter a normas jurídicas la actuación de los partidos políticos", en Revista de Derecho Político (en adelante $R D P$ ) , $\mathrm{n}^{\circ} 31$, Madrid, 1990.

3 RODRÍGUEZ DÍAZ, A.: Transición política y consolidación constitucional de los partidos políticos, Centro de Estudios Constitucionales, Madrid, 1989; del mismo autor: “El artículo 6 de la Constitución: los partidos políticos”, RDP, n 36, Madrid, 1992. 
importantes parcelas de la Teoría de la Democracia. Un primer acercamiento, reciente, puede encontrarse en un trabajo publicado en un libro en homenaje a Germán Bidart Campos, pero en él no me refería a los partidos políticos 4 . Ahora abordo aspectos parciales de la problemática indicada con la esperanza de acotarla de modo inteligible $y$, en segundo lugar, siempre que se cumpla esta primera condición, integrar con ellos y algún material complementario una monografia no del todo inútil. La circunstancia de desmembrar esta teoría en tres trabajos se debe a la solicitud de sendos eventos organizados con motivo del XXV aniversario de la Constitución española, en los que mis contribuciones no debían de exceder una cierta extensión. El lector de estos trabajos, si lo hubiere, sabrá dispensar las inevitables insuficiencias y repeticiones que en posterior versión habrán de ser subsanadas.

$Y$ ligo los tres aspectos porque, a la postre, los estudios sobre tales materias y los recursos y sentencias habidos sobre ellas terminan ligándolos de manera que uno lleva a los otros y viceversa: cuando se habla de la constitucionalidad de los partidos, se amplía el ámbito al pluralismo político y a los límites de la reforma constitucional (o a su ausencia) como referencia necesaria para entender en términos precisos ese pluralismo, lo que, a su vez, nos lleva al concepto de democracia, bien como método de adopción de decisiones, bien como forma política basada en valores, los cuales pueden erigirse en límites de su reforma, ora explícitos, ora implicitos.

En fin, esta breve contribución he de prescindir de los tópicos machaconamente repetidos en toda publicación sobre la materia: que los partidos políticos son necesarios para que haya democracia, etcétera. Dicho está y no lo repetiré más; vivimos una democracia de partidos y a ello me atengo.

\section{ETAY SU ENTORNO}

Uno de los problemas más espinosos, si no el que más, para la democracia española ha venido siendo el del terrorismo, principalmente el de ETA, ya que otros no dan lugar más que a episodios, dolorosos, sí, pero que no ponen en jaque el funcionamiento $y$ el soporte del régimen demo-

4 TORRES DEL MORAL, A.: "El instituto de la rigidez como garantía de la Constitución", en VV. AA.: Defensa de la Constitución. Garantismo y controles. Libro en reconocimiento al Doctor Germán J. Bidart Campos, Ediar, Buenos Asires, 2003, págs. 419 ss. 
crático español en los principios y valores consensuados en 1978. Cuando una organización se diversifica y camufla en diversos entes, grupos y organizaciones, dificulta la eficacia del valor (o principio) del pluralismo político, toda vez que éste impulsa a permitir la existencia de todo tipo de asociaciones, pero se encuentra con la aporía de que éstas, o algunas de ellas, tienden, a corto o a largo plazo y por vias subrepticias, cuando no delictivas, a cercenar dicho pluralismo, al menos en una parte del territorio nacional.

Es el viejo dilema de la libertad para los enemigos de la libertad con el que tiene que lidiar todo régimen democrático: si bloquea, prohíbe o disuelve la existencia de estos grupos, parece que contradice la solemne proclamación de la libertad y del pluralismo político, que la Constitución española erige en valores superiores del Ordenamiento jurídico, como también la libertad ideológica y de creencias que consagra el artículo 16 del mismo texto fundamental; pero si tolera en su seno la actividad de partidos y agrupaciones que siembran el terror entre quienes ni piensan, ni actúan, ni votan como ellos, entonces el régimen democrático está dejando crecer un peligrosísimo cáncer hasta su última fase de metástasis.

ETA ha sabido dotarse a través de los años de esa plural y compleja organización, de manera que tenía (o controlaba) desde empresas mercantiles hasta un partido político y un grupo parlamentario, pasando por organizaciones juveniles y un largo etcétera. Sus actos delictivos (secuestros, extorsiones denominadas eufemisticamente «impuesto revolucionario", asesinatos, atentados, amenazas...) parecian manchar tan sólo al ente madre (ETA), pero no a sus entes interpuestos, que aparentemente hacían política $o$ actividades mercantiles en el mundo arcangélico del pluralismo y del libre mercado mal entendidos.

Herri Batasuna ha sido a todas luces el brazo político-institucional de ETA, tanto cuando revestía la forma de mera coalición de partidos, como, más adelante, cuando fue legalizado como partido político unitario. Hubo un intento de impedir tal legalización, lo que habría reportado al sistema democrático español no muchas, pero sí algunas ventajas en el orden electoral y financiero. Pero, a mi juicio, el Poder Judicial español no estuvo a la altura de las circunstancias y su mal entendimiento del pluralismo político llevó al resultado de la citada legalización, lo que dio todavía más alas al terrorismo etarra 5 .

5 Algunas de estas consideraciones pueden leerse en mi Prólogo al libro de J. Tajadura Partidos políticos y Constitución, Civitas, Madrid, 2004. Este libro, de lectura recomendable, analiza la Ley de Partidos de 2002 y la Sentencia del Tribunal 
Desde entonces, el juego entre la separación aparente de Batasuna y ETA; el formalismo jurídico del Estado de Derecho español, que hacía como que disimulaba esa real conexión, a la que no oponía la firmeza deseable (no sin frecuentes protestas y honda preocupación de los damnificados en el País Vasco y en el resto de España), y una cierta pasividad judicial contra Batasuna (no contra ETA) han presidido las relaciones políticas del Estado español con toda la Comunidad Autónoma Vasca, incluidos su Gobierno y sus partidos políticos, a los que oficialmente se consideraba, en su totalidad, como legales y constitucionales. Ésta es la historia de un desatino que no tiene paralelo en todo el mundo, ni siquiera en Irlanda, con ser éste el ejemplo más utilizado en su favor por el terrorismo etarra.

Porque lo que procede teóricamente no es dar una respuesta satisfactoria al dilema antes planteado, sino de poner de manifiesto que no se trata de un verdadero dilema. Pues, efectivamente, a los enemigos de la libertad no hay que negarles libertad legitima alguna (¿pueden ser expresión de la libertad los actos ilegítimos?), sino de negarles, como a todo ciudadano, la libertad de delinquir impunemente. Pues, si bien las asociaciones no pueden delinquir, según reza la doctrina penalista más acrisolada, sí pueden hacerlo sus miembros, $y$, si actúan en nombre o de forma claramente representativa de la misma (incluso atribuyéndole a ésta tal actitud - no sólo su ideología - violenta y extorsionadora), fácil es la conclusión de que éste es el carácter, más allá de los términos formales que benévolamente consten en sus estatutos, de dicha asociación, partido o agrupación. Consiste, pues, en no caer en la trampa de, a fuer de defender el pluralismo, no querer ver las actividades de ciertos grupos tendentes diáfanamente a eliminarlo, al menos en cierta parte del territorio nacional.

\section{LA MUY DEFICIENTE LEGISLACIÓN SOBRE PARTIDOS DE 1978.}

Este dislate político y jurídico en el que hemos vivido los españoles durante tres décadas (dejo aparte el "tiempo" franquista por ausencia de

Constitucional 48/2003, de 12 de marzo, sobre la misma. (Una versión más abreviada del mismo puede verse en su trabajo "La dimensión externa del principio de constitucionalidad de los partidos políticos en el Ordenamiento jurídico español", Teoría y Realidad Constitucional, ${ }^{\circ}$ 12-13, UNED, Madrid, 2004, págs. 223-249.) Este presente trabajo mío, que se redactó inicialmente antes de dicho libro, pero que se publica después, se sitúa en un parecido orden de consideraciones, aunque con algún que otro matiz discrepante, más formal que de fondo. 
un régimen constitucional) ha comenzado a quebrar en 2002 por la acción casi simultánea del Poder Judicial y del Gobierno/Parlamento; o lo que es igual: con la actuación del juez Garzón contra el denominado "entorno de ETA" y con la promulgación de la Ley 6/2002, de 27 de junio, de Partidos Políticos, como comentaremos más adelante.

Interesa resaltar, como ya he hecho en otros lugares, que toda la regulación jurídica de los partidos anterior a la mencionada Ley ha estado lastrada por el tic antifranquista del constituyente, el cual adoptó muy claramente el franquismo como antimodelo. Por eso puso especial empeño en introducir el pluralismo político (atención: sólo el político) como uno de los valores superiores del Ordenamiento jurídico: artículo $1^{\circ} .1$. Y por eso también la definición constitucional de los partidos políticos en orden a sus funciones (art. $6^{\circ}$ ) dice que expresan el pluralismo político, lo que no se dice de otros institutos, como los grupos parlamentarios o las instituciones de participación directa. (Sobre ello me pronuncié hace ya veinte $a^{a n ̃ o}{ }^{6}$ ) El constituyente $-y$ no le faltaban razones históricas para elloestaba decididamente inclinado a favorecer la constitución de partidos que estructuraran políticamente España y redujeran la política a magnitudes manejables. Lo cual ya se había hecho en el Decreto-ley electoral de 1977 y se seguiría haciendo en la legislación de desarrollo de la Constitución.

Esta actitud, ya hemos dicho que explicable, llevó a las mismas Cortes Constituyentes, en función de Legislativo ordinario, a producir la Ley de Partidos (1978), prácticamente coetánea de la Constitución (aunque se repita demasiado que era preconstitucional), pues se redactó cuando ya estaba fijado el texto de nuestra norma suprema, si bien la Ley de Partidos se promulgara unos días antes. Dicha Ley era técnicamente lamentable, pues, de un lado, aunque la propia Constitución exige a los partidos respeto a la Constitución y a la ley, $y$, además, una estructura interna y un funcionamiento democráticos, al hilo de lo establecido por el constitucionalismo de la segunda posguerra (Francia, Italia, Alemania, Portugal). prescribía un modelo de estatuto mínimo de los partidos demasiado escueto, en el que faltaban cuestiones nucleares, como la existencia o no de corrientes internas y su eventual regulación, la justicia interna del partido en orden a las sanciones que éste podía imponer a sus militantes, y prescribia una estructura organizativa escuálida, en la que

6 TORRES DEL MORAL, A.: Principios de Derecho Constitucional Español, Publicaciones de la Facultad de derecho de la Universidad Complutense, Madrid, $4^{\mathrm{a}}$ edic., 1998, págs. 83 y 96. 
cabía cualquier opción, o casi. De otro lado, la regulación del control de los partidos, tanto la previa a la inscripción como la posterior, pero sobre todo la primera, era de una elementalidad rayana en la ingenuidad, puesto que, con ayuda de la doctrina científica y - todo hay que decirlo- del propio Tribunal Constitucional- se imponía el registro administrativo automático a poco que el partido guardara las formas en sus estatutos, no siendo los funcionarios del Registro de Partidos sino meros robots más ligados por la necesidad de que no hubiera sospecha alguna de intervencionismo de la Administración en el nacimiento de un partido que por el principio de legalidad de la actuación administrativa que prescribe el artículo 103.1 de la Constitución?. Lo verdaderamente llamativo es que una reciente sentencia delTribunal Constitucional confirma la doctrina de la verificación administrativa inicial como reglada, sin más control, con argumentos bastante objetables 8 .

La idea rectora de esta actitud era la de inscribir a los partidos a todo evento y luego ya se encargaria el Poder Judicial (a ser posible, poco) de suspenderlos o disolverlos vía artículo 22 de la Constitución, que regula el derecho de asociación, el cual remite a las leyes penales. La rectificación (y sólo a medias) de tamaña ingenuidad ha tardado en llegar veinticinco años. De hecho, como recuerda J. Tajadura, bajo la ley anterior ningún partido político fue declarado ilegal ${ }^{9}$.

Resultado: más de 1500 partidos, algunos de los cuales no lo son, sino que están inscritos 20 veces, como partido de ámbito nacional y una vez más por Comunidad Autónoma, más Ceuta y Melilla. La imagen atomizadora que ello refleja no se corresponde tanto con la realidad. Además, si bien en la política local tienen relieve partidos pequeños, no sucede lo mismo con la política nacional, en la que sólo ha habido, desde 1977 hasta la fecha, de ocho a doce grupos parlamentarios en el Congreso de los Diputados.

7 El artículo $6^{\circ}$ de la Constitución exige a los partidos respeto a la Constitución y a la ley. El artículo 103.1 requiere de la Administración que actúe con sometimiento pleno a la ley y al Derecho. Ambas expresiones son equivalentes, toda vez que la Constitución forma parte, encabezándolo, del Ordenamiento jurídico. Como subrayo en el texto, la aplicación usual de la Ley de Partidos de 1978 casi eximía a los partidos del referido respeto e impedía a la Administración cumplir con las exigencias del citado artículo 103.1 constitucional.

8 STC 5/2004, de 16 de enero, FJ 9.

9 TAJADURA, J.: Partidos políticos y Constitución, ob. cit., pág. 52, nota 25. 
Son, pues, muy pocos los auténticos partidos españoles existentes ${ }^{10}$ : hay algunos que no han participado o no participan ahora en los procesos electorales, tampoco lo hicieron en la campaña del referendo de la OTAN; es decir, no cumplen las funciones que les atribuye el artículo $6^{\circ}$ de la Constitución. La legislación alemana, más explicitamente y mejor,les requiere estabilidad y participación en las elecciones federales o de los Länder. En realidad no pasan de ser clubes de pensamiento, si no fuera porque no piensan y además los auténticos clubes de pensamiento son organizaciones de masas en comparación con estos partidúnculos o partidillos, que lo único que quieren es que se les facilite el censo electoral para venderlo en el mercado.

Ha habido otros partidos que no eran sino grupos de delincuentes que únicamente pretendían no expresar el pluralismo político, sino acabar con él y con el sistema que los cobija y les brinda tan sustanciosas garantías de inscripción y subsistencia, así como establecer un régimen monista, al menos en su territorio. Es decir, tampoco cumplen las condiciones de su régimen jurídico constitucional expresado en el citado artículo $6^{\circ}$. A mi juicio, expresado en otro lugar, «el partido político es la asociación constituida y registrada como tal para participar en las instituciones de manifestación de la voluntad popular y concurre efectivamente a ellas»"11. Ahora, a esta definición, he de agregar, según estamos viendo, que los partidos son asociaciones especiales, precisamente por las funciones públicas que les atribuye el Ordenamiento jurídico.

Es el Tribunal Constitucioneal quien da la pauta para tal concepto cuando asevera que "Ios arts. 6 y 22 [de la Constitución] deben interpretarse conjumta y sistemáticamente...y... debe reconocerse que el principio de organización y funcionamiento interno democrático y los derechos que él derivan integran el contenido del derecho de asociación cuando éste sobre la variante asociativa de los partidos políticos (la cursiva es mía)" 12 . Por consiguiente, dicho Tribunal, seguido por el Supremo, sustenta una concepción material de los partidos, que es la que hace suya la controvertida Ley Orgánica 6/2002, según la cual concepción los partidos son “realidades complejas, en las que concurren elementos asociativos cualificados

10 A ello me he referido en la obra antes citada (Principios...) también desde su primera edición ( $4^{\mathrm{a}}$ edic. cit., pág. 355). En sentido similar, JIMÉNEZ CAMPO, J.: "Régimen jurídico de los partidos y Constitución", en Cuadernos y Debates, Centro de Estudios Constitucionales, Madrid, 1994, pág. 38.

11 TORRES DEL MORAL, A.: Principios..., ob. y ed. cit., pág. 355.

12 STC 56/1995, de 12 de marzo, FJ 3; recoge la misma doctrina la STC 6/2004, de 16 de enero, FJ 2. 
por el ejercicio de funciones de relevancia pública siempre al servicio de la formación y expresión de la voluntad popular y por ello a medio camino entre el poder público y la asociación privada (la cursiva es mía)" 13.

\section{NECESIDAD DE MODERNIZAR DICHA LEGISLACIÓN. CONVERGENCIA DE LAS ACCIONES LEGISLATIVAY JURISDICCIONAL EN TORNO A LA SUSPENSIÓN, DISOLUCIÓN E ILEGALIZACIÓN DE LOS PARTIDOS POLITICOS.}

Así, pues, la necesidad de una moderna Ley de Partidos era evidente, sobre todo después de ver qué utilización había hecho Herri Batasuna de las ventajas y facilidades que le brindaba el Estado de Derecho español, a la que se sumaba la actitud de sus aplicadores, visible, sobre todo cuando el Poder Judicial, a pesar de la oposición del Gobierno (entonces ejercido por el PSOE) legalizó a Herri Batasuna, ordenando su inscripción como partido político (hasta aquel momento había sido un mero agregado de partidos, asociaciones y organizaciones sin estructura partidaria). A mi modo de ver, insisto, la legislación entonces en aquel momento no obligaba a una lectura tan condescendiente con las organizaciones cuyo verdadero programa era sintonizar y servir de plataforma al terrorismo. Es decir, los motivos que ha habido ahora para ilegalizar a Batasuna ya existían entonces (o eran muy parecidos) para no legalizarla como partido, sólo que sin ley de partidos, $y$ con Código Penal. En consecuencia, Herri Batasuna adquirió personalidad: jurídica de partido, con todos los beneficios jurídicos correspondientes, sobre los que no voy a entrar, con lo que continuó la sucesión infinita de asesinatos $y$ de secuestros y la presencia de ministros en los entierros. La democracia española se mostraba débil, al menos, en este punto.

Hacía falta, por consiguiente, una Ley de Partidos más completa en lo que concierne a la estructura interna de éstos y no ya más exigente en lo que se refiere a su posible ilegalización constitucional, sino simplemente que se planteara y resolviera de alguna forma este problema. Más aún: se hacía necesario, o, por lo menos muy conveniente, aprovechar el envite para codificar toda esta materia, incluyendo la financiación de los partidos, sus relaciones con los grupos parlamentarios, etcétera.

Pues bien, no es eso lo que hace la Ley Orgánica 6/2002, de 27 de junio, de Partidos Políticos, que se limita a regular la posible disolución de los partidos y que añade algunos elementos al modelo de estatuto mínimo

13 STC 48/2003, de 12 de marzo, FJ 5; reitera en STC 6/2004, de 16 de enero, FJ 4. 
de los mismos, sin llegar a abarcar todas las posibles cuestiones que en este punto pueden plantearse. En cuanto a las relaciones entre los partidos y los grupos parlamentarios, ni siquiera la roza, siendo precisamente en este punto en el que se está poniendo a prueba la aplicación práctica de la ley, con la actitud adoptada por el Parlamento Vasco. Y es que la ley, sin ser de caso único, sí obedece a un único propósito, al menos de momento: abordar el problema de Batasuna o como pretenda llamarse esta organización en cada instante.

La ley es técnicamente superior a la anterior en todo lo referente a la creación y registro de los partidos políticos (que fuera peor era realmente difícil). La exigencia de que los promotores no hayan sido penalmente condenados por asociación ilícita o por algunos de los delitos previstos en los títulos XXI a XXV del Código Penal (delitos contra la Constitución, contra el orden público, delitos de traición o contra la paz, independencia y Defensa Nacional, o bien contra la Comunidad Internacional) me parece muy puesta en razón. Pero esta prohibición no pesa sobre los afiliados, de manera que basta con tomar la cautela de que, de entre los muchos posibles miembros del partido, no figuren como promotores aquéllos. Algo, como vemos, que apenas entorpece el nacimiento de un partido.

Pero no ha sido al Gobierno, como órgano director de la política nacional, a quien se debe la iniciativa de este enfrentamiento del problema, sino al Gobierno y a la Oposición, con sus respectivos grupos parlamentarios de apoyo. He aqui el pacto (en este caso, el Pacto Antiterrorista) como modo de dirección política, en el que, en su momento inicial desaparece, por colaboración, la Oposición, al menos, la más relevante, pero, una vez alumbrado el cual, cada protagonista recupera su función, siendo la Oposición la que controla la ejecución del pacto por parte del Gobierno, hasta el punto de romperlo o denunciarlo en caso de grave discrepancia, como ocurrió a fines de la legislación 2000-2004 con el denominado Pacto por la Justicia.

Añadamos que la tramitación de la Ley se cruzó con la actuación penal del juez Garzón, el cual, mediante auto, suspendió a Herri Batasuna $y$ a todo el complejo de asociaciones y entes que componen lo que ha venido en llamar el "entorno" de ETA, por considerar que no son sino organizaciones a su servicio, es decir, que son realmente ETA con otra veste jurídica. Evidentemente esta convergencia legal y jurisdiccional no fue inútil:

a) El Parlamento Navarro aplica el auto del juez Garzón, disolviendo el Grupo Parlamentario de Batasuna y retirándole las subvenciones (y esto de la economía es sumamente importante, quizás sea lo más eficaz que cualquier otra medida). Incluso ha dejado en suspenso las iniciativas del Anterior Grupo Parlamentario de Batasuna. 
b) Mientras tanto, el Parlamento Vasco declara nulo dicho auto, 0 bien aplaza las medidas a adoptar para pedir informes. Poco después el Presidente de la Cámara dijo en plena sesión que en la. misma no había ningún grupo parlamentario ilegal.

c) También se ha aplicado, al menos en Navarra, a los grupos municipales.

d) Batasuna cambió el nombre de algunos de sus grupos municipales en unos sitios sí y en otros no, dependiendo, claro está, del juego de mayorías y minorías de cada Ayuntamiento.

e) Batasuna ha cambiado sus sedes a pisos privados o a asociaciones locales.

f) Ha habido algunas manifestaciones de la izquierda abertzale sin gritos ni pancartas de apoyo a ETA. Pasados unos meses, han vuelto a oírse tales gritos, pero no con la osadía ni el desparpajo de antes.

g) En cambio, los individuos electos mantienen su acta. Pero éste es otro problema.

$Y$ es que, aunque en toda la actuación de Batasuna haya no poco de fraude de ley, se ve que ésta, la ley, y los autos judiciales infunden respeto. El terrorismo valora que la lucha contra él va en serio, se siente acosado, se repliega y se ve con menos fuerza.

Por lo demás y como era de esperar, los partidos Batasuna, Herri. Batasuna y Euskal Herritarrok fueron ilegalizados en aplicación de esta: ley ${ }^{12}$ y recurrieron al Tribunal Constitucional en amparo, amparo que les. fue denegado ${ }^{13}$. Así también, fueron anuladas casi todas las agrupaciones: de electores que se constituyeron para las elecciones municipales inmediatas 14 , de las cuales sólo algunas encontraron amparo del Tribunal: Constitucional, quedando disueltas casi todas ellas ${ }^{15}$.

12 STS de 27-III-2003, Sala Especial del artículo 51 de la LOPJ.

13 SSTC 5 y $6 / 2004$, de 16 de enero.

14 STS de 3-V-2003, misma Sala.

15 STC 85/2003, de 8 de mayo. 


\section{DIVISIÓN DE LA DOCTRINA ACERCA DE LA CONSTITUCIONALIDAD DE LA LEY ORGÁNICA 6/2002, DE 27 DE JUNIO, SOBRE PARTIDOS POLÍTICOS}

Pero vayamos a la ley. La doctrina se ha dividido profundamente en torno a la constitucionalidad o no de la ley que comentamos. En diversos actos y seminarios a los que he asistido (Toledo, Bilbao, Madrid, Ávila, etc.) he detectado varias posiciones, que podrían resumirse del modo que sigue:

a) Una postura decididamente defensora de su constitucionalidad, más cargada de consideraciones políticas que jurídicas, y que podríamos representar con el Pfr. Roberto Blanco: la democracia tiene que defenderse por los medios más variados - civil, penal, político y administrativo - para garantizar el pluralismo.

b) Una segunda, totalmente crítica con la Ley, representada por el Pfr. Javier Pérez Royo, que plantea la cuestión en torno al artículo 22 de la Constitución, como precepto esencial en materia de partidos políticos, por ser el que regula el derecho de asociación, y el Código Penal, como regulador de los tipos bajo los cuales cabe la suspensión o disolución de las asociaciones, incluidos los partidos políticos. (Esta posición tiene origen en la sostenida por J. Jiménez Campo ${ }^{16}$ y más extensamente por $\mathrm{I}$. de Otto en su monografía Defensa de la Constitución y partidos políticos, secundada por el Tribunal Constitucional y por buena parte de la doctrina17, que se manifiesta contraria a la democracia militante, entendida como democracia persecutoria del pluralismo y que niega la libertad a los enemigos de la libertad. Hacia la misma época, J. J. Solozábal se pronunciaba en términos similares ${ }^{18}$.) Por su parte, el Pfr. Francisco

16 JIMÉNEZ CAMPO, J.: "La intervención estatal del pluralismo", Revista Española de Derecho Constitucional, $\mathrm{n}^{\circ}$ 1, Madrid, 1981, págs. 173: "No vemos en la referencia del artículo 6 al respeto a la Constitución y a la ley, base alguna para colegir que la Constitución pretende excluir de la legalidad a los grupos animados por una idea de Derecho -o por un modelo de sociedad - distintos, o aun contradictorios (...) no hay, en este sentido, más 'mínimos constitucionales' que los penalmente protegidos". $Y$ éstos se encuentran en el artículo 22 constitucional.

17 OTTO, I. de: Defensa de la Constitución y partidos políticos, Centro de Estudios Constitucionales, Madrid, 1985: el artículo 6 de la Constitución "no parece ofrecer fundamento alguno para afirmar que el constituyente español quiso o simplemente permitió establecer un sistema de defensa de la Constitución frente a los partidos anticonstitucionales..."

18 SOLOZÁBAL. J. J.: "Sobre la constitucionalización de los partidos políticos en el Derecho Constitucional y en el ordenamiento español", Revista de Estudios Políticos, $n^{\circ} 45$, Madrid, 1985, pág. 163: la prohibición de un partido político contrario a los principios esenciales de la Constitución "chocaría frontalmente con la aceptación constitucional del pluralismo y con la no prohibición de la reforma del título preliminar (de la Constitución)". 
Bastida arranca de una concepción de la democracia basada no en la mayoría, sino en la minoría (minoría que esta ley no respeta); en otras palabras: la defensa de la democracia equivale a la del pluralismo y esta ley lo dificulta; bastaría, para lo que quiere, con el Código Penal. Se trata, por tanto, según dicho autor, de una ley innecesaria, al menos en estos aspectos más coercitivos.

c) Otros colegas ven en la Ley varios escollos insalvables: conceptos jurídicos indeterminados, sala enjuiciadora, etc., en cuya función esperaban una sentencia del Tribunal Constitucional que eliminara los preceptos relativos a dichos pormenores. Así, por ejemplo, el Pfr. Luis Aguiar ha cuestionado (pero no él solo) la ilegalización de Herri Batasuna por su silencio ante los crimenes de ETA; $y$ otro han criticado duramente la atribución de la competencia juzgadora a la Sala que prevé el artículo 61 de la Ley Orgánica del Poder Judicial, bien por entender que no reunía la condición de juez predeterminado por la ley, bien por la falta de especialización de sus miembros integrantes.

d) Una cuarta, que, sin mengua de detectar tales defectos (para unos, más; para otros, menos) en la ley, entendía que podían ser subsanados mediante una oportuna sentencia interpretativa del Tribunal Constitucional. En esta posición me encuadré desde el principio $y$ es, afortunadamente, la que ha hecho suya el Alto Tribunal con la Sentencia, ya citada, 48/2003, de 12 de marzo. EI Pfr. Tajadura, de la Universidad del País Vasco, ha escrito un libro, ya citado aquí (al que ha tenido la amabilidad de anteponer un prólogo mío), en el que adopta una posición parecida a ésta, pero menos crítica con la ley porque considera que, fuera de razones de oportunidad o de posibles soluciones a diferentes puntos de la misma (por ejemplo, la conveniencia de que, mediante una reforma de la Ley Orgánica del Tribunal Constitucional, se hubiera conferido la competencia juzgadora a éste, conforme al modelo alemán), las opciones de la ley comentada tienen acomodo en la Constitución si la interpretamos (aquélla y ésta) sistemáticamente. En similar posición se instala E. Vírgala, también acorde con la constitucionalidad de la ley, pero apuntando matices a la misma por su deficiente técnica jurídica ${ }^{19}$.

19 VíRGALA, E.: "Los Partidos políticos ilícitos tras la LO 6/2002", en Teoría y realidad constitucional, $\mathrm{n}^{\circ}$ 10-11, UNED, Madrid, 2003. 
e) Y finalmente, la posición adoptada por el Pfr. Pedro de Vega, quien, un tanto drásticamente, apoyado en el principio clásico salus populi suprema lex esto, entiende que, cuando el Estado, que es el espacio político de la libertad, es'puesto en jaque y se lo pretende desmembrar, no hay ni siquiera que polemizar juridica y un tanto bizantinamente acerca de la constitucionalidad de las leyes: lo que hay que hacer es salvar el Estado.

En cuanto a los partidos políticos, éstos se alinean claramente según que sean de "ese entorno" o participen en el Gobierno del País Vasco y los demás. Sólo Izquierda Unida queda en el limbo del titubeo, precisamente por su "doble naturaleza» de ser una fuerza política de ámbito nacional y, a un tiempo, partícipe en el Gobierno de dicha Comunidad Autónoma.

\section{ANÁLISIS DE LA LEY. SENTENCIAS DELTRIBUNAL CONSTITUCIONAL 48/2003, DE 12 DE MARZO, Y 5Y 6/2004, DE 16 DE ENERO}

¿Cuál es la posición que sostengo respecto de la comentada ley? Ante todo, he de decir que las palabras subsiguientes son más de planteamiento de problemas que un análisis acabado de la ley. Por eso me fijaré en sólo unos aspectos o flecos.

\subsection{Fuera complejos.}

Mi primera consideración es más política que jurídica. Tras veinticinco años de padecimiento del terrorismo, de crispación de la sociedad (principalmente de la vasca, pero no sólo de ella) e incluso de incomprensión de la ineficacia del aparato estatal en su eliminación, el legislador, con un amplio consenso, pues en este punto contó con el apoyo de los dos grupos parlamentarios mayores (y de los partidos políticos "correspondientes" por mor del denominado Pacto Antiterrorista), decidió que no era posible seguir con actitudes acomplejadas para ganarse el perdón de las democracias de su cultura jurídica y política. ¡Fuera complejos! El problema del terrorismo ha de ser abordado desde todos los ángulos que permita el Estado de Derecho sin reparar en si parecerá bien a los países aliados o no, aunque suponiendo que, en las actuales circunstancias, apoyarían la posición española. En algunos de éstos, problemas semejantes han recibido una réplica mucho más contundente ( $v$ menos acorde con la juridicidad estatal) sin que el asunto haya 
aguantado unos pocos días en la "primera" de los periódicos. Así que, con mayor motivo, el problema de las organizaciones terroristas y sus adláteres podía ser abordado por el legislador, con la presunción de legitimidad que éste tiene en un régimen democrático constitucional.

De otro lado, la finalidad de la Ley Orgánica 6/2002 no es acabar con un partido, sino asegurar a todos los ciudadanos el poder hacer política sin miedo y a vivir sin el peso del terror encima. $Y$ precisemos además que la Ley requierè reiteración de las conductas tipificadas para considerarlas insertas en los tipos establecidos de suspensión o ilegalización de los partidos en cuestión. Lo que es bien indicativo, al menos en esto, de una actitud prudente a la hora de proceder a una operación tan delicada como es la de suspender o disolver un partido político.

6.2. El ambiente internacional antiterrorista después de la destrucción de las Torres Gemelas de Nueva York y el casi simultáneo ataque al Pentágono.

Siguiendo con estimaciones políticas, el momento en que se abordó la redacción de la Ley era el más propicio para los propósitos del legislador, puesto que imperaba (y sigue imperando) en todo el mundo un evidente miedo al terrorismo y una correspondiente actitud de intolerancia frente a los intolerantes. Los etarras y los miembros de Herri Batasuna han dejado de ser considerados por algunas democracias como románticos separatistas, cuando no un grupo de liberación nacional, y han pasado a engrosar las listas de grupos terroristas, con todas las consecuencias que esto trae consigo, por ejemplo, en la seguridad y rapidez de las extradiciones solicitadas por España y, en su caso, en la detención y enjuiciamiento en tales países. Es decir, el legislador y la democracia española se han visto beneficiados ( $\mathrm{si}$ se puede hablar en estos términos cuando se trata de tragedias) por el execrable crimen de Nueva York y Washington. Ante tales acontecimientos las democracias occidentales han cerrado filas y no van a oponer (no han opuesto de hecho) ninguna reserva a la opción legislativa española.

\subsection{Aspectos criticables u opinables de la Ley}

Pasando a consideraciones jurídicas, y una vez que el Tribunal Constitucional se ha pronunciado negativamente sobre el recurso de inconstitucionalidad interpuesto por el Gobierno Vasco contra la ley comentada, hemos de decir que ésta, en efecto, presenta algunas facetas 
criticables, o, al menos, opinables, en cuya exposición o enumeración no debe importar el pronunciamiento del Alto Tribunal, puesto que nos encontramos en sede académica.

En primer lugar, se ha desaprovechado la ocasión para codificar todo el Derecho de partidos, abordando y sistematizando cuestiones tan importantes ( $y$ por ahora diseminadas o no tratadas) como la financiación de los partidos, incluida la obtenida con ocasión de las campañas electorales, un más acabado modelo de estatuto mínimo de los partidos (aunque algo ha mejorado la somera y deficiente redacción que hacia la Ley de 1978), la relación entre partidos políticos y grupos parlamentarios y un etcétera generoso en el que no voy a detenerme. Al parecer, de nuevo consideraciones políticas de urgencia en la luçha antiterrorista persuadieron al legislador de dejar para ulterior ocasión estas cuestiones tan importantes.

En el modelo de estatuto mínimo de los partidos políticos falta, desde luego, un tratamiento de la existencia o no de corrientes internas en los mismos. Éste es un problema muy delicado, puesto que un partido es una unidad de acción política y no puede diversificar su mensaje ni su programa en tantos cuantas corrientes o subcorrientes internas existan en él. Acierta la ley, por tanto, a mi juicio, al no abordar dicha cuestión y dejarla a la libre configuración de los propios partidos, algunos de los cuales, como sabemos, niegan la posibilidad oficial de tal existencia sin que ello signifique que se sustenta en una estructura autoritaria.

Cuestión diferente es la denominada justicia interna de los partidos, esto es el procedimiento a seguir en los conflictos que el partido tenga con sus afiliados o grupos de ellos. Aunque la regulación de los derechos y obligaciones de los afiliados, asi como de las posibles sanciones e incluso expulsión de éstos es más garantista que la de la ley de 1978, no cubre todas las eventualidades. Habría sido deseable una mayor precisión.

¿Son exigibles totalmente las garantías de tutela judicial efectiva del artículo 24 constitucional? Entonces, un miembro del partido no se vería definitivamente expulsado del mismo hasta pasados varios años; tal es la intrincada maraña de garantías del precepto mencionado, que pueden estar justificadas cuando se trata de la relación del ciudadano con el Poder Judicial, pero no tanto cuando se trata de la que existe entre un partido político y una persona que pertenece a él voluntariamente.

Hay casos que son claramente de expulsión inmediata, como hacen los árbitros en el deporte, aunque haya garantías a posteriori. Hay otros que ofrecen un mínimo de duda, en los que un juicio sumario y abreviado (un juicio rápido, como se dice ahora) sería suficiente. Y los hay más com- 
plicados, en los que algunas, al menos algunas, de las garantías del artículo 24 deberian ser de aplicación obligatoria.

\subsection{La actividad de los partidos y su posible ilegalización}

Llegamos, en fin, al controvertido artículo $9^{\circ}$ de la ley en cuestión, en el que se regula la actividad de los partidos.

1) Se exige a los partidos que en su actividad respeten los valores constitucionales, con especial referencia a los principios democráticos, los derechos humanos y el pluralismo.

2) Lo contrario, cuando se produzca de forma reiterada y grave, podrá comportar su declaración de ilegalidad.

Lo que más interesa en esta reflexión sobre tan agudo problema es la regulación de los supuestos en los que es procedente la ilegalización de un partido, que es realmente el leiv motiv del cuerpo legal examinado. A este respecto, hemos de recordar que una de las primeras sentencias del Tribunal Constitucional asevera: «En un sistema de pluralismo político... la función del Tribunal Constitucional es fijar los límites dentro de los cuales pueden plantearse legítimamente las distintas opciones políticas» 20 . Con palabras no muy distintas, es lo que atribuye a la propia Constitución en otra de sus resoluciones: "La Constitución es un marco de coincidencias suficientemente amplio como para que dentro de él quepan opciones políticas de muy diferente signo" 21.

Así, pues, estamos hablando de marco y de límites. Los límites pueden ser considerados de dos formas muy diferentes: a) como conformación de un marco o campo de juego político, dentro del cual caben todas las opciones políticas; b) como definición de la licitud constitucional y fijación del punto final de las opciones políticas, mas allá del cual se cae en el abismo de lo antijurídico, en el ancho campo de la ilegalidad o de la inconstitucionalidad. Sobre esto no se ha reflexionado demasiado entre nosotros a la hora de explicar el pluralismo y el consenso constitucionales.

Admite el Tribunal Constitucional la defectuosa redacción de la Ley que analizamos, su dudosa técnica legislativa, cuando parece que en los apartados 2 y 3 del artículo $9^{\circ}$ suma unas conductas a otras introduciendo

20 STC 3/1981, de 2 de febrero, FJ 3.

21 STC 11/1981, de 8 de abril, FJ 7. 
confusión respecto de cuáles son, en definitiva, las que pueden comportar la ilegalización de un partido. Se trata, según el Tribunal (y una lectura detenida de los referidos preceptos así lo indica) de dos apartados complementarios: el segundo habla de los caracteres genéricos del comportamiento rechazable $y$ el tercero ilustra (acaso innecesariamente) con conductas concretas ese repudio del Ordenamiento22. No hay, por consiguiente, aunque pudiera parecerlo, cierta amalgama de los preceptos 9.2 y 9.3 que pudieran crear inseguridad jurídica. $Y$ los conceptos jurídicos indeterminados, que también se le atribuyen, son salvables. Lo son mediante las frecuentes interpretaciones que el Tribunal Constitucional se ve necesitado de establecer para sujetar la ley dentro de la Constitución, haciendo continuamente hincapié en la gravedad y reiteración de las conductas fijadas a favor del terrorismo en una u otra de sus manifestaciones.

Como contraste de Derecho comparado, recordemos que el artículo 21 de la Ley Fundamental alemana establece que pueden ser disueltos los partidos que por sus fines o por el comportamiento de sus miembros adherentes tiendan a desvirtuar o a eliminar el régimen demoliberal o a poner en peligro la República Federal de Alemania. En comparación con este precepto alemán, la ley española es sumamente suave y condescendiente con los «enemigos de la libertad", por decirlo con palabras usuales en la doctrina cuando trata de estas cuestiones.

En suma, como asociaciones especiales que son, en función de lo cual disfrutan de prerrogativas que se les niega a las demás asociaciones, entre las cuales no es la menor la de su financiación pública, los partidos tienen que responder a su definición por el artículo $6^{\circ}$ de la Constitución y atenerse a las exigencias de este mismo precepto, de toda la Constitución y de la ley, entre las que acaso las más importantes sean las de su estructura interna $y$ su funcionamiento democrático. Por eso, el Tribunal Constitucional, que en otras ocasiones ha tendido a aproximar su estatuto jurídico al de las asociaciones, sostiene ahora: "Un partido político no es, en definitiva, una asociación que simplemente persigue un fin político o tiene intereses de ese carácter. Es una asociación que aspira a traducir una posición política en normas de Derecho... a cuyo servicio se constituye... La relevancia constitucional de est e contenido explica que la Constitución imponga a los partidos políticos condiciones que no exige a las asociaciones comunes.... 23 (cursiva mía). Y, aunque insiste en el control previo de mera

22 STC 48/2003, de 12 de marzo, FJ 10. Insiste en el reproche de la defectuosa redacción en STC 5/2004, citada, FJ 17.

23 STC 5/2004, de 16 de enero, FJ 9. 
verificación reglada y concluye que el control efectivo ha de ser necesariamente a posteriori, agrega que también de tracto sucesivo, es decir, que se sigue exigiendo en tanto el partido siga existiendo. "Y las llamadas causas de ilegalización y disolución no son otra cosa que la especificación de los casos en los que el legislador orgánico ha entendido que no concurren en la realidad los elementos definidores del concepto constitucional de partido que se dieron previamente por supuestos cuando el partido afectado se constituyó e inscribió como tal partidon. Lo que se da, pues, no es una sanción, sino una "revisión de una calificación en Derecho que...se presumió... (y) se ha demostrado después que no merece..." 24 (cursivas mías). Es mi entender que en materia tan delicada no deben hacerse tantas presunciones ni suposiciones, sino un control más serio y detenido.

Por eso, como han dicho muy sensatamente R. Morodo y P. Lucas Murillo de la Cueva, a pesar de que el Código Penal sea la barrera principal en el control de los partidos, caben formas de control de la constitucionalidad que alcancen a sus fines, puesto que la posibilidad de reforma íntegra de nuestra Constitución «no significa que consienta cualquier cosa ni que admita cualquier método para lograrla». 25

\subsection{No se trata de un juicio penal}

No es procedente hablar aquí de tipos, sino simplemente de conductas, porque no se trata de un juicio penal, sino de un juicio de constitucionalidad. Es ésta una idea que reitera el Tribunal extensamente en la STC 5/2004, de 16 de enero. Más aún, la disolución prevista en la Ley Orgánica de Partidos Políticos "no constituye una sanción en sentido propio", porque, dice citando su propia doctrina de la Sentencia 48/2003, de 12 de marzo, «antes que un fin propiamente retributivo, las causas de ilegalización y disolución previstas en la Ley responden a una finalidad de garantía... de las condiciones definidoras de los partidos políticos»26. Por ende, tampoco cabe argumentar como defensa la presunción de inocencia, que sólo es esgrimible en el juicio penal27.

Por eso, a juicio de nuestro más alto tribunal, no hay en la ley vulneración alguna del principio non bis in idem, puesto que el Código Penal cri-

24 Misma sentencia y fundamento jurídico.

25 MORODO, R., y LUCAS MURILLO DE LA CUEVA, P.: El ordenamiento constitucional de los partidos, UNAM, México, 2001, pág. 137

26 SSTC 5/2004, de 16 de enero, y 48/2003, de 12 de marzo, F.J 9 de ambas.

27 STC 5/2003, citada, FF.JJ. 9, 14 y 15. 
minaliza personas físicas y la Ley de Partidos ilegaliza asociaciones especificas, ilegalización en la que, como queda dicho, no hay componente punitivo alguno 28 .

\subsection{Apoyo tácito al terrorismo}

Algunas de las mencionadas ilustraciones de conductas que pueden dar lugar a la ilegalización de un partido obligan al intérprete a no fáciles consideraciones, pero puede superarse la duda inicial. Sólo la primera de ellas es más discutible: dar apoyo político, expreso o tácito al terrorismo, legitimando las acciones terroristas... o exculpando y minimizando su significado y la violación de derechos fundamentales que comporta. La doctrina no ha dejado de destacar esta "inculpación" del partido por su justificación tácita o expresa del terrorismo.

¿Qué es apoyo tácito? Parece querer decir la ley que el que calla otorga. Desde luego, no siempre es así. ¿Lo es en este caso? Deducir del silencio una conducta de legitimación o exculpación de actos terroristas parece un tanto aventurado.

El supremo intérprete de la Constitución no se emplea muy a fondo respecto de esta cuestión en la STC 48/2003, si bien admite, con cierto apoyo en el Tribunal Europeo de Derecho Humanos ${ }^{29}$, que la legitimación del terrorismo por parte de un partido político puede llevarse a cabo de modo implícito, callando, pero, eso sí, llevando a cabo actos concluyentes en determinadas circunstancias. La calificación como supuesto de ilegalización de esos silencios acompañados de actos no significa una vulneración de la libertad de expresión. (Se me ocurren, como ejemplos de justificación tácita, el acuerdo de un Ayuntamiento de dedicar una calle a una persona reiteradamente condenada por tales delitos, o su declaración de hijo predilecto del pueblo, o la declaración de día de fiesta local el de un atentado terrorista, etc.). He aquí un importante aspecto de la sentencia interpretativa que exponemos 30 .

Además, para que el referido silencio sobre los hechos terroristas signifique su tan criticada justificación tácita, debe darse unido a otras circunstancias (que de por sí ya suponen connivencia con el terrorismo) y ser reiterativo, de manera que un silencio aislado no comporta tan grave con-

28 STC 48/2003, citada, FJ 9.

29 SSTEDH de 30 de enero de 1998 y de 13 de febrero de 2003

30 STC 48/2003, citada, FJ 10. 
secuencia jurídica como es la suspensión o, mucho menos, disolución del partido en cuestión ${ }^{31}$. Sólo queda la duda de si entonces era necesario incorporar dicho silencio al elenco de causas de ilegalización, puesto que las aludidas circunstancias concomitantes ya podrían constituir de suyo causas válidas para la misma.

No obstante, en la STC 5/2004 sí se extiende el Tribunal sobre este punto, confirmando la doctrina expuesta. Reconoce, en principio que en la anterior sentencia no entró apenas a considerar este problema. $Y$, al hacerlo ahora, corrobora que la negativa de un partido político a condenar atentados terroristas puede constituir, en determinadas circunstancias, una actitud de apoyo tácito o de legitimación del terrorismo porque puede tener un cierto componente de exculpación o minimización del mismo. No es, pues, algo inocuo: en un contexto de terrorismo, que es presentado como única salida de un pretendido conflicto histórico, la negativa a condenar "adquiere una evidente densidad significativa por acumulación", por presentarlo como reacción inevitable contra una agresión previa e injusta del Estado españo/32, de lo que cabe inferir, según habia dicho el Tribunal Supremo, un compromiso con el terror sobre la base de una equidistancia entre éste y el Estado 33 . Porque como dice el Tribunal en otra ocasión, basta con que el partido o la agrupación electoral en cuestión haga constar su inequivoco distanciamiento de ETA; el no hacerlo es expresión de una deliberada voluntad de no desmarcarse de ella; es una afirmación de su voluntad de no condenar sus prácticas terroristas. 34

Así, pues, sin ser los aludidos preceptos un dechado de técnica legislativa, es posible su interpretación jurídica acorde con los principios constitucionales. Los criticados (con razón) conceptos jurídicos indeterminados no son por sí mismos una vulneración de la seguridad jurídica, sino, todo lo más, trabajo para abogados, fiscales y jueces ( $y$ también para nosotros, como estudiosos).

Esto es justamente lo que ha hecho el Tribunal Constitucional y lo que esperábamos algunos, porque ya ha ocurrido en otras ocasiones. No es que el endoso de problemas políticos a este Tribunal sea deseable, pero, una vez que los tiene ante su mesa, no puede eludirlos y su obligación es la de "salvar" la ley hasta donde pueda, máxime en este caso, de elevada gravedad política; labor que tiene límites, claro está: los propios

31 Misma Sentencia, FF.JJ. 10 y 11.

32 STC 5/2004, citada, FJ 18. Cfr. FJ 11.

33 STS de 27-III-2003, Sala Especial del artículo 61 de la LOPJ.

34 STC de 27 de mayo de 2004.

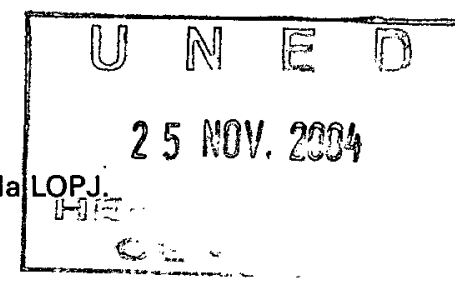

(C) UNED. Revista de Derecho Politico.

N. ${ }^{\circ} 60-2004$ 
principios constitucionales que trata de cohonestar. Casi estaríamos por decir que el Tribunal Constitucional no podía hacer sino lo que ha hecho, pues anular por inconstitucional ciertos pasajes de la ley (siendo posible salvarlos, aun con esfuerzo) comportaba un paso atrás en la lucha contra el terrorismo que el Tribunal no estaba dispuesto a dar (o, por mejor decir, a significarse como el órgano que lo diera). Se percibe aquí que, pese a todo su poder, el Tribunal Constitucional no sólo es un órgano menesteroso (como dijo en su día Rubio Llorente), pues no actúa de oficio y ha de esperar a que otros órganos o miembros de órganos lo pongan en marcha, sino que, llegado el caso, no puede eludir el ser corresponsable de la dirección política del Estado.

Por consiguiente, que el comportamiento descrito, salvo la duda enunciada, lleve a la disolución o a la suspensión judicial del partido, es una consecuencia jurídica coherente, añadiendo el artículo 10 de la ley estudiada las garantías del Código Penal, las de la Ley de Enjuiciamiento Criminal y la del juez competente.

\subsection{Competencia juzgadora}

En fin, otro de los "flecos" que la ley ha tenido a bien dejar para el debate académico es el de la atribución de la competencia juzgadora a la Sala anteriormente creada por el artículo 61 de la Ley Orgánica del Poder Judicial, para lo cual ha habido que reformar esta Ley que nos ocupa. Como referencia, digamos que en Francia la ilegalización de los partidos se lleva a cabo por medio de un decreto presidencial y en Alemania, por la jurisdicción del Tribunal Constitucional Federal; por eso, si se prohibe un partido en un Land, ello no comporta su inconstitucionalidad a nivel federal si no se ha pronunciado expresamente sobre ello el citado Tribunal.

Este extremo de la ley española ha levantado críticas por su supuesta vulneración de la garantía del juez natural, del juez competente predeterminado por la ley, e incluso por la centralización de todos estos casos en Madrid. Pero es evidente que la ley puede atribuir nuevas competencias a Salas ya existentes. Esta no es una Sala ad hoc, aunque sus anteriores competencias estuvieran muy lejanas de ésta. Habría sido seguramente más indicado que la ley analizada en este trabajo hubiera modificado la Ley Orgánica del Tribunal Constitucional para añadirle a sus competencias esta otra, dado que de un juicio de constitucionalidad se trata (en este caso, de partidos, no de normas). Concuerdo en ello con lo defendido por el J. Tajadura en el libro citado y con lo sostenido por el F. Rubio Llorente en un artículo de prensa. 


\subsection{Democracia militante}

El recurso del Gobierno Vasco incidía en que la ley impugnada se instala en una posición de democracia militante, en el sentido de que impone sus valores negando los diferentes y los opuestos, de lo que resulta una obvia negación del pluralismo político. El Tribunal Constitucional y, tras él, el Supremo, niegan tal aserto y acaso el argumento preferido para ello es el de que la Constitución española permite la revisión total de su texto, sin cláusula alguna de intangibilidad 35 . Posteriormente, el Tribunal Constitucional ha vuelto a negar la condición militante de nuestra democracia 36 .

A mi juicio, ambos tribunales yerran al aceptar acríticamente el concepto de democracia militante que nos ha llegado de cierta literatura jurídico-pública del pasado siglo. Hoy por democracia se entiende otra cosa, o, dicho de otro modo, se entiende algo mucho más complejo: es método de gobierno, sí, pero también valores y principios compartidos por la generalidad de la ciudadanía (he aquí la idea de pacto como inseparable de la de Constitución) y delineadores de una forma de vida política basada en el respeto $y$ en la tolerancia, pero $-y$ esto es muy indicativo- que quiere seguir siendo democracia porque sabe (sabemos los ciudadanos) que no hay régimen político preferible a ella $y$, por consiguiente, sólo es democrático lo que permite) que siga habiendo democracia, esto es, lo que permite la constante renovación del sistema dentro de sus coordenadas democráticas. Así, en España, los cuatro valores superiores del artículo 1.1 de la Constitución, más la dignidad humana, más media docena de otros valores que pueden extraerse de dicho texto y de su Preámbulo nos persuaden de que la Constitución no es éticamente neutral ni es políticamente sólo procedimental, sino algo más.

Por eso, aunque no haya en nuestra norma suprema preceptos de intangibilidad y pueda ser reformada íntegramente, se entiende que ha de serlo no sólo mediante método democrático, sino para sustituirla por otro texto también democrático, pues, de lo contrario, su artículo 1.1 sería absolutamente absurdo, puesto que dice propugnar unos valores les decir, defenderlos, ampararlos, según el Diccionario de la Real Academia Española de la Lengua) y, sin embargo, ni los ampara ni los defiende, sino que los deja aniquilar sin resistencia. Si la Constitución tiene prevista su

35 STC 48/2003, citada, FJ 7; STS de 27 de marzo de 2003, citada.

36 STC 5/2004, citada, FJ 17. 
defensa y si sólo hay propiamente Constitución en un régimen democrático, la democracia ha de arbitrar igualmente su defensa, si es que ambas no son la misma cosa. ¿Qué diferencia hay entonces entre defender la democracia y militar en sus valores en contra de quienes quieren implantar una autocracia y en contra de los métodos que usan para ello? Entendida en este sentido, toda democracia es militante y no puede dejar de serlo, sin que este aserto signifique, obviamente, acusación ni desdoro alguno.

Lo curioso es que algunos constitucionalistas defienden las dos tesis: la existencia de valores y/o principios inmodificables en la Constitución y la imposible prohibición constitucional o legal ( sobre la prohibición o suspensión penal no hay debate) de partidos que atenten contra ellos.

\subsection{Las candidaturas de las agrupaciones de electores}

La anulación de una candidatura presentada por una agrupación de electores no comporta, dice el Tribunal Constitucional, una causa de inelegibilidad no prevista por la Ley Electoral, sino un criterio para valorar el comportamiento del partido, si lo hace regularmente, porque puede significar una solidaridad con el terror. Ninguna persona está obligada a retractarse de lo hecho, pero, si no lo hace, el partido sabe que incluirla reiteradamente en sus listas electorales puede tener la lectura dicha. El precepto correspondiente, además, sólo tiene proyección hacia el futuro y se juzga a partir de una trayectoria de conjunto y dilatada en el tiempo ${ }^{37}$. He aquí otro elemento interpretativo de esta sentencia, sin el cual la ley quedaría al borde de la inconstitucionalidad, porque podría significar un cercenamiento ilegítimo del derecho de participación política.

Pero el Tribunal Constitucional, consciente de lo dedicado que es cercenar el derecho de sufragio pasivo de un ciudadano, puso especial cuidado, corrigiendo a la Junta Electoral de Zona de Pamplona y al propio Tribunal Supremo, y sostuvo que únicamente puede admitirse dicho efecto cuando concurren otros varios factores, tales como la naturaleza y relevancia de la vinculación de la agrupación electoral con los partidos ilegalizados, el desempeño poe alguno de sus componentes de cargos públicos relacionados con los partidos disueltos, la existencia de condenas penales,

37 STC 48/2003, citada, FJ 13. 
etc. Si no concurren acumuladamente varias de estas circunstancias, no puede anularse la candidatura pues significaria castigar a la agrupación electoral por un juicio de intenciones ${ }^{38}$. No obstante lo cual, han seguido anulándose candidaturas en los meses siguientes. En cuanto a la comprobación del nombre del nuevo partido y su posible coincidencia con otros ya existentes o recién desaparecidos, sólo puede denegarse la inscripción en tales casos o cuando el nombre del partido en ciernes contradiga palmaria, patente o manifiestamente el Ordenamiento. $\mathrm{He}$ aquí un último -y de fácil comprensión-elemento interpretativo de la sentencia 39 .

Hay en el mismo artículo $9^{\circ}$ de la ley otras cautelas que apenas necesitan comentario, salvo el de que el legislador sabe muy bien con quién se las gasta, como se vio en las siguientes elecciones municipales, en las que Herri Batasuna se quiso camuflar en diversas agrupaciones de electores, que fueron anuladas por el tribunal Supremo 40 , extremo confirmado por el Tribunal Constitucional 41 , como diremos más adelante. Igualmente se ha detectado el cambio fraudulento de domicilios, de nombres de diversas organizaciones coadyuvantes, de nombres de grupos municipales, etc., como ya hemos apuntado.

\section{OTROS ASPECTOS DE LA LEYY DE LAS SSTC 48/2003Y 5/2004}

Pasando sobre la existencia en la referida sentencia de alguna contradicción teórica acerca de la naturaleza jurídica de los partidos, que vuelve a aparecer en la que resuelve el recurso de la ilegalización de Batasuna y Euskal Herritarrok42, pero que es irrelevante para esta reflexión nuestra, nos referiremos a otros aspectos aireados en la polémica doctrinal y que nosotros hemos considerado con menos detenimiento en las páginas anteriores.

a) La iniciativa para la ilegalización

Ha sido criticado que la iniciativa para la ilegalización de un partido pudieran tomarla el Congreso y el Senado, es decir, por hipótesis, adver-

38 STC 176/2003, de 10 de octubre, FJ5.

39 STC 48/2003, citada, FJ 21.

40 STS de 3 de mayo de 2003.

41 STC $85 / 2003$, de 8 de mayo.

42 STC 48/2003, citada, FJ 5; STC 5/2004, citada, FJ 17.

(C) UNED. Revista de Derecho Político. 
sarios políticos de los ilegalizables, lo que parecía dejar en manos de la mayoría la supervivencia de las minorías. La redacción se cambió durante el iter legislativo, de manera que dichas Cámaras sólo podrán dirigirse al Gobierno, para que sea éste, además del Ministerio Fiscal, quien solicite la declaración de ilegalidad o suspensión del partido.

\section{b) ¿Ley de caso único?}

Tampoco estamos, como dice el recurso del Gobierno Vasco, ante una ley de caso único. Es evidente que, aunque el propósito del legislador fuera ilegalizar Herri Batasuna, la Ley es aplicable a cualquier otro supuesto similar que se presente.

\section{c) Control de los partidos}

Ante todo, las dos sentencias aceptan 43 , como no podía ser de otro modo, la existencia de un control de los partidos políticos a pesar de que la Constitución no atribuyera esta función al Tribunal Constitucional, sino, por exclusión, al Poder Judicial. Como adujo el representante procesal del Senado, los partidos son una especie del género asociaciones que bien pueden regularse por separado precisamente por su especialidad, e incluso así está previsto en la Ley de Asociaciones y lo acepta la STC 5/2003, que define los partidos por la especialidad de sus funciones, lo que exigen unas condiciones que no se requieren del resto de las asociaciones. El control, a la hora de la inscripción debe de ser una revisión reglada, sin juicio de intenciones. Será más tarde, cuando se den las causas de ilegalización si se comprueba que aquella calificación jurídica de partido presumida a la hora de la inscripción, no era correcta. A mi me parece un tanto alambicada la explicación, si es que no incurre en contradicción.

Como sabemos, ya existía tal control en la Ley de Partidos, de 1978, por defectuosa que fuera. No estamos, pues, ante una estrategia repentinamente pensada forzando el Ordenamiento 44 .

No hay, pues, injerencia de la Administración, cuya actividad es reglada y atinente sólo a los aspectos formales, por lo que el partido adquiere personalidad jurídica con su inscripción en el Registro existente

43 SSTC $48 / 2003$ y 5/2004, citadas, FF.JJ 9 en ambas.

44 STC 48/2003, citada, FF.JJ. $4 y 5$. 
al efecto. Pero el régimen de partidos no tendría por qué ser igual, a este respecto, que el régimen general de las asociaciones. En la garantía de tal comportamiento de la Administración reside un elemento interpretativo más de esta sentencia45. A mi juicio, este elemento era un tanto innecesario por cuanto ya antes de esta ley (aunque la precedente lo silenciara o lo dijera muy mal) un partido no registrado no tenía personalidad jurídica como partido, sino únicamente como simple asociación.

d) ¿Podría haberse hecho una gradación de sanciones, en vez imponer una sola, tan grave?

Así opina el Gobierno Vasco y, en efecto, ésa era una posible opción del legislador, pero el Tribunal Constitucional, apoyándose en el Tribunal Europeo de Derechos Humanos, entiende que las conductas referidas son tan graves, además de ser reiteradas, que el margen de apreciación que siempre tiene la autoridad nacional para calibrar el peligro de las mismas para la democracia valida la opción del legislador, a lo que se añade la garantía judicial 46 .

\section{e) Irretroactividad.}

El Tribunal Constitucional desecha que, para la aplicación de estos criterios de la Ley, se juzguen actividades anteriores a la misma. Las actividades relevantes, a los efectos de esta ley, son sólo las futuras. Lo que no impide contemplar la trayectoria pasada para hacer una valoración conjunta de un partido y sin embargo, permite apreciar la sucesión fraudulenta de partidos. Estamos ante otro elemento interpretativo, también bastante alambicado, de esta sentencia.

45 Misma Sentencia, FJ 20.

46 Misma Sentencia, FJ 13. 


\section{CONCLUSIÓN}

Todos o casi todos estos aspectos han sido manifestados en el recurso de inconstitucionalidad interpuesto por el Gobierno Vasco, recurso un tanto atropellado, generalista y poco preciso, del que discrepo en general y particularmente en dos puntos: en primer lugar, el referente a que, si el constituyente no estableció un control de constitucionalidad de los partidos es porque los asemejó, a los efectos de control, a las asociaciones comunes; $y$, en segundo término, como ya he apuntado, que la ley adopta la posición de democracia militante e impide con ello el pluralismo político.

Yo discrepo tanto de lo primero como de lo segundo. Los partidos son asociaciones, sí, pero especiales por las funciones públicas, incluso políticas, que les están encomendadas (artículo $6^{\circ}$ de la Constitución), lo cual, si no impone, tampoco impide que sean regulados por una ley diferente de la de asociaciones, y así venía siendo, como es sabido, desde los tiempos mismos del proceso constituyente. $Y$ discrepo (por lo expuesto en una página anterior, a la que remito) de lo segundo, es decir, de que no quepa en nuestro Ordenamiento jurídico un concepto de democracia militante y de que ésta sea sólo neutral o democracia como método.

El resto de la Ley, incluidos los efectos de la ilegalización, son el resultado correspondiente de lo que llevamos visto, sin que haya sorpresas, aunque, como hemos apuntado, sí se han producido problemas jurídico-políticos, como los concernientes a las agrupaciones de electores que ha promovido el partido ilegalizado, lo que ha llevado a los Tribunales Constitucional y Supremo a pronunciarse de nuevo, con general coherencia pero con algún fundamento jurídico más que opinable.

\section{EPÍLOGO: ACTIVIDAD DE LOSTRIBUNALES SUPREMO $Y$ CONSTITUCIONAL ESPAÑOLES, DEL PARLAMENTO EUROPEO Y DELTRIBUNAL EUROPEO DE DERECHOS HUMANOS}

1. Al respaldo (aunque matizado) dado por el Tribunal Constitucional a la LO 6/2003 de Partidos Políticos sucedió una actividad trepidante. Primero fue la ilegalización de Batasuna, Herri Batasuna y Euskal Herritarrok acordada por la Sala Especial del Tribunal Supremo47, a la que sucedió la resolución por el Tribunal Constitucional del recurso de amparo

47 STS de 27 de marzo de 2003. 
contra la anterior sentencia, en la que el supremo intérprete de la Constitución respaldaba al Tribunal Supremo48. Aparecieron entonces agrupaciones de electores (promovidas por los partidos ilegalizados) que presentaron candidaturas a las elecciones municipales inmediatas, ya convocadas. Como en Derecho procesal electoral los plazos son muy breves, precisamente en garantía de la participación política y de las organizaciones que a ella acuden, el Tribunal Supremo hubo de resolver en tan sólo cuatro dias los procesos (instados por la Abogacía del Estado y por el Ministerio Fiscal) de impugnación de dichas candidaturas, resolución que fue acorde con la demanda y contraria a los intereses de las agrupaciones referidas ${ }^{49}$. Y, recurridas éstas de nuevo en amparo en dos días, el Tribunal Constitucional, a su vez, hubo de resolver en otros dos, desestimando los recursos y confirmando, con algún matiz, las sentencias del Tribunal Supremo ${ }^{50}$. Toda esta rapidez fue contestada por los grupos interesados como una conculcación del derecho de defensa; lo que también tiene un poco de ardid jurídico.Igual ha sucedido en 2004, con ocasión de las elecciones al Parlamento Europeo, a las que una agrupación de electores más o menos afín a Batasuna ha presentado una candidatura, anulada por el Tribunal Supremo 51 , anulación que, tras el correspondiente recurso de amparo, ha confirmado de nuevo el Tribunal Constitucional, bien que con un voto particular concurrente en el que se critica la brevedad de los plazos como contraria al derecho de defensa 52 .

2. De otro lado, el Pleno del Parlamento Europeo, en la reunión celebrada el día 4 de septiembre de 2003, aprobó un Informe sobre la situación de los derechos fundamentales en la Unión Europea. En dicho Informe se dice de manera expresa que la ilegalización de Batasuna en España fue llevada a cabo mediante una ley que es conforme con los «principios de libertad, democracia y respeto de los derechos humanos y las libertades fundamentales, así como del Estado de Derechon. El Informe precisa asimismo que el proyecto presentado en marzo de 2002 para prevenir y congelar la financiación del terrorismo está basado en una Resolución del Consejo de Seguridad de las Naciones Unidas y en las conclusiones del Consejo Europeo de septiembre de 2001.

\footnotetext{
48 SSTC 5 y 6/2004, de 16 de enero.

49 SSTS de 3 de mayo de 2003.

50 STC 85/2003, de 8 de mayo.

51 STS de 21 de mayo de 2004.

52 STC de 27 de mayo de 2004. Voto particular de la magistrada María Emilia Casas.
} 
Tal espaldarazo europeo a la vigente Ley de Partidos, además de arrojar un elemento más a tener en cuenta a la hora de enjuiciar su constitucionalidad, es muestra del actual ambiente internacional antiterrorista señalado en uno de los puntos anteriores. Seguramente no habría sido tan explícito si se hubiera redactado antes del terrible episodio de las Torres Gemelas. Pero el tiempo y las circunstancias también cuentan en el Derecho.

3. Sin embargo, cinco días más tarde del anterior evento el Gobierno Vasco acordó recurrir ante el Tribunal Europeo de Derechos Humanos la Ley que estamos comentando como vulneradora de derechos reconocidos en el Convenio Europeo de Derechos Humanos. (Pero añadamos que, a la postre, en 32 municipios navarros, en los que se anularon las candidaturas disfrazadas de Herri Batasuna, tampoco se han podido presentar las de Unión del Pueblo Navarro y del Partido Socialista de Navarra-PSOE, y en uno ni siquiera la de Eusko Alkartasuna, para las correspondientes elecciones parciales el 26 de octubre, por miedo de los vecinos a figurar en ellas.)

Los últimos pronunciamientos del Tribunal Europeo de Derechos Humanos sobre ilegalización de partidos se han referido a casos producidos en Turquía y en Polonia. En todos los primeros apreció vulneración del Convenio por parte del Estado de Turquía, pero no así en el caso de Polonia.

El Tribunal suele conectar el artículo 11 del Convenio (libertad de reunión, asociación y sindicación) con el artículo 10 (libertad de expresión), puesto que en muchos casos, lo que se pone en cuestión son declaraciones, comunicados, etcétera, del partido enjuiciado o de sus miembros más representativos.

El Tribunal Europeo de Derechos Humanos, en los referidos casos resueltos, considera que la intervención de los poderes públicos perseguía un fin legítimo (el de la integridad territorial y la seguridad nacional). Sin embargo, para que sus medidas sean proporcionadas, es insuficiente que las ideas expresadas sean molestas o inquietantes, por cuanto esto es admisible en democracia; no así las que atenten precisamente contra ésta. Es decir, que en un programa de partido puede defenderse, cómo no, la reforma de la ley e incluso de la Constitución, pero no puede defender ideas xenófobas, racistas, ni de violencia; menos aún, llevarlas a efecto.

Pero en el caso que nos ocupa no ha necesitado este Tribunal hacer uso de su propia doctrina, sino que ha inadmitido el recurso del Gobierno Vasco 53 , al cual no reconoce legitimación activa para demandar al Estado español por tratarse de una Organización Gubernamental, frente a lo que

53 Auto delTEDH de 6-II-2004. 
establecen los artículos 34 y 35.4 del Convenio Europeo combinadamente interpretados.

Queda por ver lo que el Tribunal resolverá en los recursos individuales (o de las agrupaciones de electores) presentados por el llamado "entorno de Batasuna" sobre el rechazo de sus candidaturas electorales, en los que seguramente tendrá que pronunciarse sobre el fondo del asunto. En este punto, lo más inquietante, a mi juicio, reside en esa cierta circulación de la responsabilidad desde los miembros más representativos y elevados en el organigrama de un partido político a este mismo, y de éste, a su vez, a sus miembros, aunque ahora sean menos representativos: basta con que dos de ellos hayan figurado en las candidaturas electorales del partido ilegalizado para "contaminar" la nueva en que pueda figurar de las agrupaciones electorales constituidas. Aunque, como hemos dicho antes, es evidente el fraude de ley que se busca con la constitución de tales agrupaciones electorales y su correspondiente presentación de candidaturas.

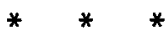

En fin, como dije al principio, trabajo para abogados, jueces y fiscales, porque las acciones y los recursos se multiplicarán en cada ocasión: reuniones, manifestaciones, presentación de candidaturas electorales por parte de agrupaciones de electores, etcétera. Y, para mayor fatiga de los tribunales y demás operadores jurídicos, muchas veces tendrán que ser abordadas las primeras y resueltos los segundos uno a uno, sin que quepa su acumulación. Aquí también hay tarea para el legislador, puesto que no debe ponerse a nuestros tribunales en la tesitura de tener que resolver cientos de recursos en cuarenta y ocho horas, dadas las fraudulentas tácticas utilizadas por las agrupaciones de electores que responden a los dictados del terrorismo. Se imponen, por tanto, las reformas legales pertinentes, incluida la de la Ley Orgánica del Tribunal Constitucional, para evitar dicha burla al Estado de Derecho. 